\title{
Cushing's Syndrome: Aftermath of the Cure
}

\begin{abstract}
Cushing's syndrome (CS) is a chronic and systemic disease caused by endogenous or exogenous hypercortisolism, associated with an increase of mortality rate due to the clinical consequences of glucocorticoid excess, especially cardiovascular diseases. After cure usually obtained by the surgical removal of the tumor responsible for the disease, the normalization of cortisol secretion is not constantly followed by the recovery of the clinical complications developed during the active disease, and it is often followed by the development of novel clinical manifestations induced by the fall of cortisol levels. These evidences were mostly documented in patients with pituitary-dependent CS, after surgical resection of the pituitary tumor. Indeed, despite an improvement of the mortality rate, metabolic syndrome and the consequent cardiovascular risk have been found to partially persist after disease remission, strictly correlated to the insulin resistance. Skeletal diseases, mainly osteoporosis, improve after normalization of cortisol levels but require a long period of time or the use of specific treatment, mainly bisphosphonates, to reach the normalization of bone mass. A relevant improvement or resolution of mental disturbances has been described in patients cured from CS, although in several cases, cognitive decline persisted and psychological or psychiatric improvement was erratic, delayed, or incomplete. On the other hand, development or exacerbation of autoimmune disorders, mainly thyroid autoimmune diseases, was documented in predisposed patients with CS after disease remission. The totality of these complications persisting or occurring after successful treatment contribute to the impairment of quality of life registered in patients with CS after disease cure. (Arq Bras Endocrinol Metab 2007;51/8:1381-1391)
\end{abstract}

Keywords: Cushing's syndrome; Cushing's disease; Hypercortisolism; Cure; Remission; Metabolic syndrome; Hypertension; Cardiovascular risk; Osteoporosis; Pituitary; Adrenal; ACTH; Cortisol; Glucocorticoid excess

\section{RESUMO}

\section{Síndrome de Cushing: Resultado da Cura.}

A síndrome de Cushing (SC) é uma desordem sistêmica crônica causada por hipercortisolismo endógeno ou exógeno, associada a um aumento da taxa de mortalidade devido às conseqüências clínicas do excesso de glicocorticóides, especialmente a doença cardiovascular. Após a cura, usualmente obtida pela remoção cirúrgica do tumor responsável pela desordem, a normalização da secreção de cortisol não é sistematicamente seguida da recuperação das complicações clínicas desenvolvidas durante a fase ativa da doença, e é freqüentemente seguida pelo surgimento de novas manifestações clínicas induzidas pela queda dos níveis de cortisol. Estas evidências foram, na sua maioria, documentadas em pacientes com SC de origem hipofisária, após a ressecção cirúrgica do tumor na hipófise. Na verdade, a despeito de uma melhoria na taxa de mortalidade, a síndrome metabólica e seu conseqüente risco cardiovascular têm se mostrado parcialmente persistentes após a remissão da doença, em estrita relação com a resistência à insulina. Anormalidades esqueléticas, especialmente a osteoporose, melhoram após a normalização dos níveis de cortisol, mas requerem um longo tempo ou o uso de tratamento específico, principalmente bisfosfonatos, para se obter a normalização da massa óssea. Uma melhora significativa ou mesmo resolução dos distúrbios mentais têm sido descritos em pacientes curados da SC, embora em vários casos o declínio cognitivo persista e a melhora psicológica ou psiquiátrica tenham sido erráticas, demoradas ou incompletas. Por outro lado, o desenvolvimento ou exacerbação de processos autoimunes, em especial as doenças autoimunes da tiróide, foram documentadas em pacientes predispostos com SC, após a remissão da doença. A totalidade dessas complicações, persistentes ou ocorrendo após o tratamento bem sucedido, contribuem para um prejuízo da qualidade de vida registrado em pacientes com SC após a cura da doença. (Arq Bras Endocrinol Metab 2007;51/8:1381-1391)

Descritores: Síndrome de Cushing; Doença de Cushing; Hipercortisolismo; Cura; Remissão; Síndrome metabólica; Hipertensão; Risco cardiovascular; Osteoporose; Hipófise; Adrenal; ACTH; Cortisol; Excesso de glucocorticóide

\section{artigo original}

\author{
Rosario Pivonello \\ Maria Cristina De Martino \\ MONICA DE LEO \\ LIBUSE TAUCHMANOVÀ \\ ANTONGIULIO FAGGIANO \\ GAETANO LOMBARDI \\ annamaria Colao
}

\author{
Department of Molecular and \\ Clinical Endocrinology and \\ Oncology, "Federico II" \\ University of Naples, Italy.
}


$\mathrm{C}^{\mathrm{s}}$ USHING'S SYNDROME (CS) is a chronic and systemic disease caused by endogenous or exogenous hypercortisolism. The endogenous hypercortisolism may be the consequence of an ACTH-secreting or corticotroph pituitary tumor [Cushing's disease (CD); $80-85 \%$ of cases] or ACTH-secreting extrapituitary tumor (ectopic CS; $5-10 \%$ of cases) or may depend on an adrenal disease (unilateral benign or malignant adrenal tumors, bilateral adrenal hyperplasia or dysplasia; 10-20\% of cases) associated with an ACTH-independent cortisol overproduction (1-4).

CS is associated to a four-fold increase of mortality rate compared to normal population due to the clinical complications of hypercortisolism, especially cardiovascular diseases (5-7). The most important and frequent systemic complication of CS is represented by the metabolic syndrome, namely the combination of visceral obesity, systemic arterial hypertension, glucose intolerance, and dyslipidemia, which together with thrombosis diathesis, and the presence of increased homocysteine and decreased taurine levels, induced an increased cardiovascular risk (8-10). Glucocorticoid excess exerts multiple and complex effects on the skeletal system, including osteopenia or osteoporosis, often associated with pathological fractures $(11,12)$, osteoarthrosis (13), and osteonecrosis (14). Nephrolithiasis, together with an impairment of renal function, is also quite common, although it is usually not associated to a clinical syndrome $(15,16)$. Mental disturbances complicate great part of patients with CS and include a range of psychological or psychiatric manifestations ranging from anxiety to psychosis, such as major depression, and intellective impairment involving cognition and memory, often associated with cerebral atrophy (17-20). Hypercortisolism may also interfere with the function of different endocrine axis and glands, mainly thyroid and gonads. Indeed, central hypothyroidism together with primary thyroid disorders (21), central hypogonadism together with polycystic ovarian syndrome and menstrual disturbances in women, or sexual dysfunction in men, and consequent damage of fertility $(22,23)$, and an impairment of $\mathrm{GH}$ secretion (24) are frequently observed in patients with CS. The totality of these complications induces a significant impairment on the quality of life of patients with CS (25).

The severity of the clinical complications of CS suggests the necessity of a prompt cure of the disease, or at least a rapid remission of hypocortisolism, in order to limit the long-term morbidity and mortality associated with glucocorticoid excess. The treatment of CS is strongly dependent on the etiological form of the syndrome. Surgery is the first-line treatment for all types of CS. However, it is usually effective in curing adrenal-dependent CS, but it often fails to induce disease remission in the ACTH-dependent CS, which also displays difficulties in the diagnostic procedures and the causative tumor localization (1-4). In particular, the treatment of $\mathrm{CD}$ generally requires different approaches including pituitary and adrenal surgery, pituitary-targeted and adrenal-targeted pharmacotherapy, and radiotherapy (1-4). The difficulties in the diagnosis and treatment, and the consequent long-lasting exposure of patients with CD to glucocorticoid excess do not ensure the complete recovery of the clinical complications associated with the disease, so that a specific clinical syndrome seem to persist in patients cured from CD. On the other hand, the normalization of hypercortisolism or the onset of hypocortisolism after disease cure might induce the occurrence of novel clinical manifestations, which participate in defining the clinical syndrome of patients cured from CD. It is important to outline that the ectopic CS, usually sustained by a neuroendocrine tumor, with a variable degree of differentiation and aggressiveness, and a malignant behavior in a certain percentage, is a rare condition, with complicated diagnosis and treatments, and poor prognosis. Therefore, no studies have definitely evaluated the clinical picture after disease cure. The same concerns regard the adrenal-dependent CS associated with adrenocortical malignant tumors.

The current review summarizes the present evidences regarding the consequences of the cure of CS, and emphasizing either the persisting clinical complications of the disease or the occurring clinical manifestations induced by the disease cure. The majority of the studies on this topic focused on $\mathrm{CD}$, due to its relative higher prevalence, and the greater complexity in its management, and refers to the remission or cure induced by surgery. Focusing on CD, this review will also outline comparing data on the different forms of CS or response to different treatments, where available.

\section{CONCEPT OF CURE AND REMISSION OF CUSHING'S SYNDROME}

The cure of CS requires the removal of its causative lesion, and the consequent recovery from hypercortisolism. However, the treatment of CS does not always reach these objectives. In particular, in $\mathrm{CD}$, the surgical removal of pituitary tumor can be followed by persistence or recurrence of hypercortisolism in $40-50 \%$ of cases (26). On the other hand, the use of pharma- 
cotherapy often normalizes cortisol secretion, without affecting the pituitary tumor. Therefore, the cure of CS can be confirmed only after a decade from the removal of the pituitary tumor, when cortisol secretion remains normal and the disease recurrence can be excluded. On this basis, the term remission is better used to define the recovery from hypercortisolism after treatment, mainly surgery. Theoretically, the remission of hypercortisolism consists in the normalization of urinary cortisol levels with restoration of the physiological serum cortisol circadian rhythm. However, the surgical removal of the pituitary tumor rarely leads to this physiological condition, being able to induce a mild hypocortisolism or maintain a mild hypercortisolism (27). Therefore, different criteria to define the remission of hypercortisolism have been proposed, ranging from the occurrence of definitive or transient post-operative hypocortisolism to the persistence of hypercortisolism becoming suppressible after dexamethasone administration (28-33). Since the confirmation of disease cure can be obtained only a decade after surgery, in the last years several studies tried to identify an early index of disease cure. Particularly, undetectable $(<1.8 \mathrm{mg} / \mathrm{dL})$ morning serum cortisol, within 2 weeks after surgery, has been reported as the best predictor of long-term disease cure (31). However, discordant data have been reported afterwards in different studies, demonstrating that the post-operative undetectable morning serum cortisol was not predictive of long-term disease cure (32) or even proposing the detection of morning serum cortisol levels lower than $5.0 \mathrm{mg} / \mathrm{dL}$ after three months from surgery as better predictor of long-term cure, with a positive and negative predictive values of $87 \%$ and $90 \%$, respectively (33). As an alternative to the measurement of morning serum cortisol levels, the early responsiveness of cortisol to corticotrophin-releasing hormone $(\mathrm{CRH})$ or desmopressin-stimulating test has also been proposed as predictor of disease recurrence $(34,35)$, but these tests are not routinely and widely used in the post-operative assessment of CD.

\section{THE CLINICAL PICTURE OF CUSHING'S SYNDROME AFTERMATH OF THE CURE}

The remission or cure of CS is characterized by recovery from hypercortisolism, corresponding to a normalization of cortisol secretion, or the occurrence of hypocortisolism, requiring specific replacement treatment. The evaluation of the consequences of CS remission needs to consider the appropriateness of replacement treatment of patients with permanent hypocortisolism, being the over-replacement or the under-replacement able to influence the clinical picture of patients with CS after disease remission. The recovery of hypercortisolism is usually accompanied by a significant improvement of the clinical picture, although a number of clinical complications, arisen during the active disease, totally or partially persist, and a number of clinical complications, not arisen during the active disease, may develop after disease cure.

\section{Mortality}

The mortality rate of patients with CS, mainly CD, before and after remission has been evaluated in three main studies (5-7). The first study considered a Spanish population with a diagnosis of CD between 1975 and 1992, among which disease remission was obtained in around $80 \%$ of cases during these years: a four-fold higher mortality was demonstrated, mainly due to cardiovascular diseases, and associated with age, persistence of hypertension and impaired glucose tolerance (5). A second study considered a Finnish population treated for CS between 1981 and 1994, demonstrating not an increased mortality rate, but an increased morbidity rate compared to normal population (6). A recent study considered a Danish population of 166 patients with different forms of CS: the mortality rate of non-malignant forms of CS was 3.7 times higher than normal population, especially in patients diagnosed as CD but with unproven etiology, where it was around 11.5 higher than normal population. It is noteworthy that the mortality rate was only 1.7 times higher in CD patients with a clear-cut pituitary tumor, whereas it was surprisingly around 4 times higher in patients with an adrenal adenoma. The prognosis of patients with malignant disease was very poor, as almost the totality of patients died during the study. The highest mortality of patients with CS occurred during the first year after diagnosis, and the main cause is also represented by cardiovascular disease. It is important to outline that patients with CD cured by successful surgery did not have an increased mortality rate whereas those who had a recurrence of $\mathrm{CD}$ after unsuccessful surgery had a 5-time higher mortality rate than normal population (7). In summary, the results of these studies confirmed that patients with CS are affected by an increased mortality rate, whereas controversial data are available on patients cured from CS, which, however, clearly maintain a higher morbidity rate, mainly due to the increased prevalence of metabolic syndrome and cardiovascular diseases, which represents the main cause of death of patients with CS. 


\section{Metabolic syndrome}

The metabolic syndrome is a recognized clinical entity, characterized by the combination of visceral obesity, systemic arterial hypertension, impairment of glucose tolerance and/or dyslipidemia. A clinical condition resembling the metabolic syndrome is a common feature of CS $(1,8)$. This systemic complication of CS usually improves but not completely recovers after disease remission. Systemic arterial hypertension, which affects the majority of adults and half the children with CS (36), has been documented to persist in more than $25 \%$ of adult patients (37), whereas it almost always recovered in children with CS one year after successful surgical treatment (38). The most important risk factors for the persistence of hypertension after remission of CS included the severity and duration of hypertension before surgical treatment (39). These evidences suggest that, beyond the prompt diagnosis and treatment of CS, the rapid and careful control of blood pressure with antihypertensive drugs is mandatory during the active phase of the disease. During the last years, two important studies have evaluated the effect of normalization of cortisol secretion on the clinical manifestations related to the metabolic syndrome in patients with CD $(9,40)$. In a longitudinal study performed in 25 patients with CD before and one year after successful treatment, obesity, mainly characterized by a visceral or abdominal obesity due to an increased waist to hip ratio, persisted in $62,5 \%$, hypertension in $55,6 \%$, glucose intolerance in $60 \%$, hypercholesterolemia and hypertriglyceridemia in $77 \%$ and $60 \%$, respectively, of cases with the respective clinical complications before treatment, suggesting the persistence of a metabolic syndrome in a great part of patients who had remission of CD (9). These patients were demonstrated to display a metabolic condition significantly different to that of normal population but close to that of a population with similar body mass index, suggesting that the persisting visceral obesity plays a pivotal role in the maintenance of the metabolic syndrome. Similarly, in a transversal study performed in 15 patients with a stable cure from CD for at least 5 years, visceral obesity was documented in $73 \%$, hypertension in $40 \%$, impairment of glucose tolerance or diabetes mellitus in $60 \%$, and dyslipidemia in $30 \%$ of patients, displaying an increased higher incidence of metabolic syndrome compared with either normal population or population with similar body mass index (40). It is noteworthy that a state of insulin resistance with hyperinsulinemia was found in the cohort of patients cured from CD. In particular, fasting insulin levels were the best predictor of waist to hip

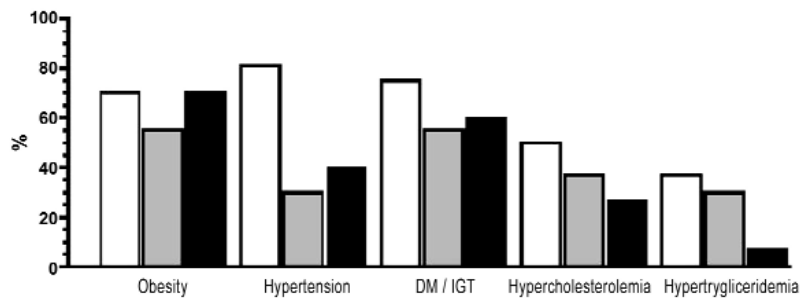

Figure 1. Prevalence of clinical manifestations of the metabolic syndrome in patients who have active Cushing's disease (white bars), patients in short-term remission (gray bars), and patients in long-term remission (black bars) from Cushing's disease. DM, diabetes mellitus; IGT, impaired glucose tolerance.

ratio and vice versa, and both parameters were significantly correlated with most of the clinical manifestations of the metabolic syndrome, confirming the documented role of visceral obesity and insulin resistance in the development of metabolic syndrome also in patients cured from CD (40). Figure I shows the prevalence of different clinical manifestations of metabolic syndrome in patients with active $\mathrm{CD}$ and in patients short-term and long-term cured from CD (8). These data indicate that either short- or long-term normalization of cortisol secretion are characterized by a persistence of a metabolic syndrome similar to that observed in active CD. Visceral obesity and insulin resistance represent the pathogenic mechanism of metabolic syndrome in patients who have active CS and those who have a history of CS (8). The strict relationship between glucocorticoids and metabolic syndrome has also been documented by the evidence of increased circulating cortisol levels in people with hypertension and glucose intolerance, and amplification of intracellular cortisol levels in the adipose tissue of people with obesity due to increased local regeneration of cortisol by the enzyme 11 beta-hydroxysteroid-dehydrogenase type l (1lb-HSDl) (4l), so that inhibitors of this enzyme have been proposed as treatment of the classical metabolic syndrome, not dependent on CS (42).

\section{Cardiovascular diseases}

Chronic exposure to glucocorticoid excess is associated with an increased morbidity and mortality for cardiovascular diseases, mainly heart stroke and heart failure, or cerebrovascular disease $(1,8)$. The increased cardiovascular risk is mainly due to hypertension as well as coagulopathy, with the consequent thrombosis diathesis of CS (43). However, an important risk factor for cardiovascular diseases is also represented by the metabolic syndrome $(1,8)$. Since hypertension and metabolic syndrome often persist after disease cure, 
the cardiovascular risk also presumably accompanies a great percentage of patients with CS for a long time after disease cure. The most evident expression of cardiovascular risk in patients with CS is the increased arterial stiffness and premature arterial atherosclerosis documented in patients with CS $(1,8)$. This vascular feature often persists after disease remission. Indeed, common carotid arteries, wall thickness and stiffness remained increased in patients with $\mathrm{CD}$ one year after successful treatment compared with normal population, although it improved compared with the active phase of the disease (9). Moreover, well-defined carotid wall plaques were detected in $32 \%$ of patients with active or cured disease (9). This atherogenic pattern is also documented in patients with $\mathrm{CD}$ after at least 5 years from the disease remission (40). Welldefined carotid wall plaques were detected in approximately $30 \%$ of patients with long-term disease remission (40). In this later study, the significant correlation between common carotid wall thickness and stiffness and degree of visceral obesity, as well as circulating insulin levels, confirmed the role of metabolic syndrome in the development of atherosclerosis of patients CD after disease cure. Figure 2 shows an example of an arterial wall plaque detected at the origin of the internal carotid artery at echo-Doppler ultrasonography, as expression of premature atherosclerosis in a patient long-term cured from CD (40). It is noteworthy that the atherogenic consequences of the metabolic syndrome seem to be worse in patients after long-term remission (40) than in patients after

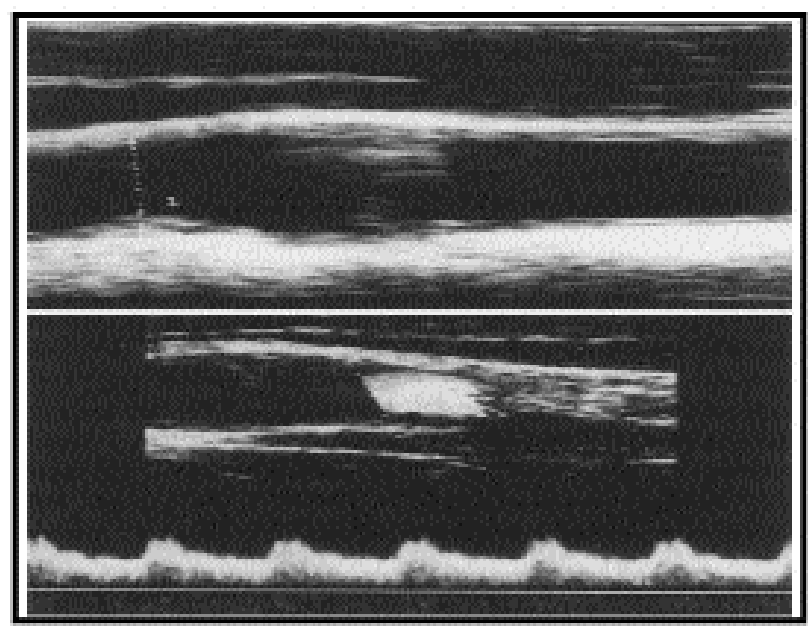

Figure 2. Echo-Doppler ultrasonography showing an example of a plaque detected at the origin of the internal carotid artery (top) and the correspondent flussimetric diagram (bottom) in a patient with Cushing's disease after long-term remission. The shaded line indicates the vessel lumen of the internal carotid artery: the line passes through the atherosclerotic plaque. short-term remission from hypercortisolism (9). This finding may be related to a more prolonged although not marked presence in the former than in the latter group of patients of visceral obesity or insulin resistance with associated metabolic syndrome, which represent a low but continuous stimulus for atherogenesis (40). In addition, an immune system rebound following the shift from chronic hypercortisolism to normal cortisol secretion or hypocortisolism may play a role in atherogenesis. Indeed, the removal of cortisolinduced suppression of the immune system has been suggested as an explanation of the increased prevalence of autoimmune diseases in patients cured from CS, allowing to hypothesize that the aggravation of atherosclerosis over time in subjects cured from CS may be partially sustained by inflammatory or immune processes damaging the vasculature, emphasized by the immune re-activation after disease remission (8). Conversely, since no abnormality of homocysteine and taurine metabolism seems to persist after remission of hypercortisolism, hyperhomocysteinemia and hypotaurinemia seem to not contribute to the persistent and progressively worsening cardiovascular risk of patients cured from the disease (10). The severity and the duration of hypercortisolism also influence the severity of atherosclerosis and cardiovascular risk in patients with cured CS (40). It has to be mentioned that in consideration to the role of coagulopathy in the development of thromboembolic events occurring in patients with CS, an anticoagulant prophylactic therapy during the active phase of the disease has been demonstrated to prevent postoperative thromboembolic morbidity and mortality in patients with CS (4446). Anyway, the totality of these evidences permits to conclude that despite cardiovascular mortality seeming to not be increased, cardiovascular morbidity definitely persists in patients cured from CS.

\section{Skeletal diseases}

Skeletal diseases represent an important complication of CS, and mainly include osteoporosis, osteoarthrosis, and osteonecrosis (1,11-14). Osteoporosis frequently complicates all types of CS, being higher in patients with ectopic CS, probably due to the severely increased circulating cortisol levels, compared to pituitary-dependent and adrenal-dependent CS $(11,12)$. Controversial data reported a higher prevalence of osteoporosis in adrenal-dependent or pituitary-dependent CS $(12,47,48)$. Bone loss is due to either direct effects of glucocorticoids on osteoblasts, osteocytes, and osteoclasts, or indirect effects of glucocorticoids on calcium, phosphorus, and vitamin D metabolism, 
as well as parathyroid function, and affects both bone formation and resorption, involving both bone matrix formation and bone mineralization (49). Bone deficiency is more severe in vertebral spine than in femoral neck, and the vertebrae are frequently affected by fractures and collapses $(11,12)$. There is a wide agreement on the progressive recovery of bone deficiency after disease remission, although discrepancies were reported regarding the time necessary to a complete recovery of bone loss (50-53), as well as on the necessity of a specific treatment to favor the normalization of bone mass $(54,55)$. Indeed, one-year treatment with bisphosphonates has demonstrated to improve bone mass either in patients with active disease or in patients with cured disease, where the beneficial effect was higher than that spontaneously obtained in untreated patients (55). It is noteworthy that osteoporosis and their direct consequences, such as vertebral fractures and collapse, are responsible for multiple spine abnormalities and deformities, which may occur in patients with CS and persist after disease cure, presumably for the entire life (13). Figure 3 shows the radiographic images of the spine in two different patients with $\mathrm{CD}$, one with active disease and the other with cured disease, where the spine condition of the latter seems to be worse than that of the former. The knowledge of osteoarthrosis in CS is presently based on case reports, which do not describe the effect CS cure on bone disease $(56,57)$. Osteonecrosis is well described in pa-
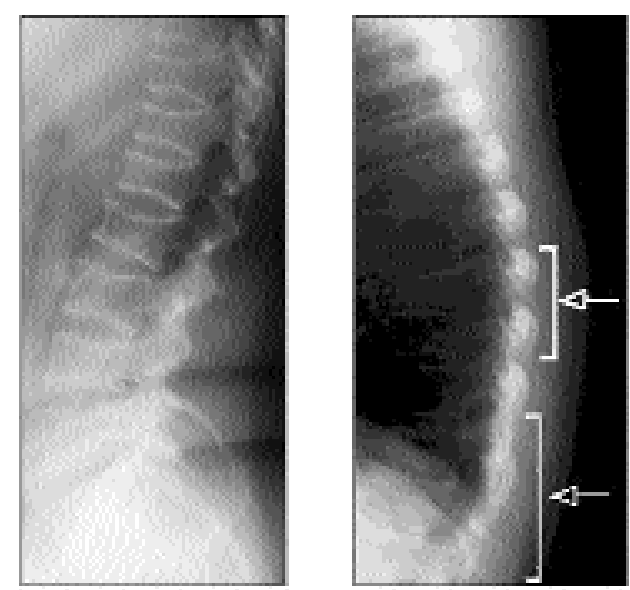

Figure 3. Radiographic images of the spine of a 27-year-old female patient with active Cushing's disease (leff) and of a 29-year-old male patient cured from Cushing's disease for three years (right). The first image shows a spine with severe osteoporosis, and collapsed vertebral bodies (Th 10, Th11, Th12, L1, L2). The second image shows a spine with diffuse and marked osteoporosis together with collapse of different vertebral bodies (Th8, Th9, Th11, Th12, indicated by the arrows). The spine picture of the cured patient seems to be worse than that of the active patient. tients with exogenous CS, but rarely in patients with endogenous CS, where sporadic cases of avascular necrosis of femoral head have been reported $(14,58,59)$. No study has focused on the effect of CS cure on this bone disease. Figure 4 shows a case of avascular necrosis at the level of the femoral head detected at magnetic resonance imaging in a patient cured from $\mathrm{CD}$ for a long period of time, which required the replacement of the femoral head.

\section{Renal diseases}

The involvement of renal structure and function in the clinical picture of CS is represented by the occurrence of nephrolithiasis and the impairment of renal clearance $(15,16)$. Silent microlithiasis were the most common clinical expression of nephrolithiasis in patients with active disease, associated with hypercalciuria, hyperuricosuria, increased urinary levels of oxalate and decreased urinary levels of citrate. The disease remission was accompanied by a significant improvement of renal stone disease, since normal excretion of calcium, urate, oxalate, and citrate was documented, and only a residual clinically silent microlithiasis was found in a small percentage of patients after successful treatment (15). Regarding the renal clearance, although no study has definitely evaluated the glomerular and tubular function in CS patients, increased excretion rate of some amino acids, together with increased urinary excretion of cystine, has been documented in patients with active $\mathrm{CD}$, but not in patients cured from CD (16). The different aspects of renal structure and function in patients with active and cured CS need to be further investigated to draw definitive conclusions regarding the influence of glucocorticoid excess and its resolution on renal activity.

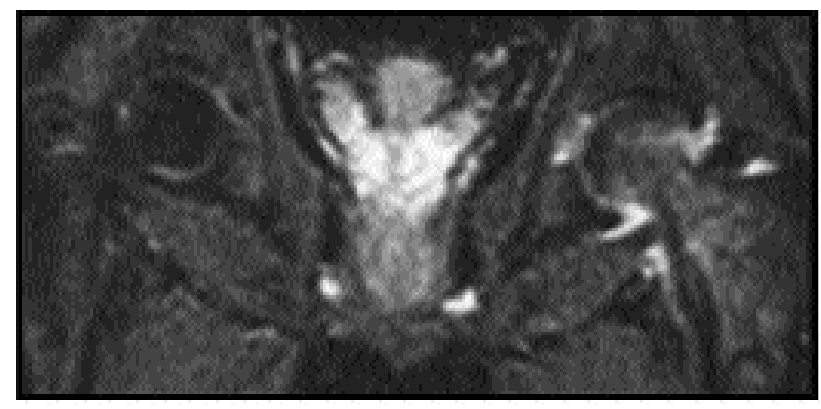

Figure 4. Magnetic resonance imaging (T2-weighted images) of the hips of a patient with Cushing's disease after long-term remission, showing a clear picture of avascular necrosis of the left femoral head, as testified by the hyperintensity of the femoral head, due to oedema, and erosion of the articular surface. 


\section{Mental disturbances}

CS is associated with mental disturbances, mainly characterized by an intellective deficiency and a psychological impairment, which have a variable clinical expression, ranging from anxiety to major depression (17-19). These mental disturbances are accompanied by structural modification of the brain, namely atrophy of specific cerebral areas (20,60-64). A multifactorial pathogenesis of the cerebral atrophy has been hypothesized including glucocorticoid-induced cell death, interference with the process of neuronal metabolism and transmission, and reduction of cerebral water content (20,60-62). The normalization of cortisol secretion following disease remission has been demonstrated to reverse, at least partially, cerebral atrophy $(20,63,64)$, suggesting that neuronal death is not the only and probably not the main mechanism by which glucocorticoids induce loss of brain volume. In line with these evidences, depression and cognitive decline in CS typically resolve with treatment of hypercortisolemia in direct relationship to the reduction in circulating cortisol levels, either obtained by surgery or medical treatment (65-67). A response rate of mental disturbances of around $75 \%$ has been described in patients cured from CS, although in several cases psychological or psychiatric improvement was erratic, delayed, or incomplete. The strict relationship between glucocorticoid excess and depression has suggested the use of antiglucocorticoid drugs as possible treatment of this psychiatric disease (68). Despite these evidences, some experiences demonstrated a persistent cognitive impairment following surgical treatment in patients with CS (69). In particular, in a population of children with CS, a cognitive decline has been demonstrated after one year from the resolution of the disease (70), demonstrating that some permanent damage of the intellective function may occur in patients with CS. It is possible to hypothesize, however, that in susceptible patients psychiatric disturbances, mainly depression, occurred during the active disease, may persist or even worsen after disease cure, in dependence on the life and disease experience of the patient, possibly supported by the loss of euphoric state induced by glucocorticoid excess.

\section{Autoimmune diseases}

Glucocorticoid excess is known to exert an inhibitory action on immune function in humans (71). In fact, patients with CS have an involution of lymphoid tissue mass and lymphopenia and present with an increased susceptibility to infections (72). An opposite phenomenon has been described in patients cured from CS.
Indeed, development or exacerbation of autoimmune diseases were reported to occur in patients who normalized cortisol secretion after remission of CS. Particularly, exacerbation of coeliac disease (73) and rheumatoid arthritis (74), and development of sarcoidosis (75) and lupus erythematosus (76) were reported in patients with different forms of CS after correction of hypercortisolism. The most frequently autoimmune diseases reported after remission of CS are thyroid immune diseases, mainly including autoimmune thyroiditis $(77,78)$ and Graves's disease (79). The prevalence of thyroid autoimmunity has been evaluated in 20 patients successfully treated from CD, demonstrating that thyroid autoantibodies were found in $20 \%$ of patients with active disease and $60 \%$ of patients with cured disease, whereas an autoimmune thyroiditis was diagnosed in none of the patients with active disease and in 35\% of patients with cured disease (80). These findings demonstrated that thyroid autoimmunity is more frequent in patients with CD who normalize cortisol secretion compared to both with patients with active disease and normal population. Figure 5 shows the prevalence of thyroid autoimmune disease in patients with $\mathrm{CD}$ during active phase of the disease and after one year of disease cure. It is noteworthy that the development of autoimmune thyroiditis in patients cured from CD is associated with the presence of thyroid nodular goiter or positive thyroid autoantibodies during the active phase of the disease, suggesting that pre-existent thyroid abnormalities, and probably genetic imprinting, are predisposing factors for the future development of autoimmune thyroid diseases after CD cure (80). Anyway, the development or exacerbation of autoimmune disease in patients with CS after normalization of cortisol secretion has been hypothesized to be related to a

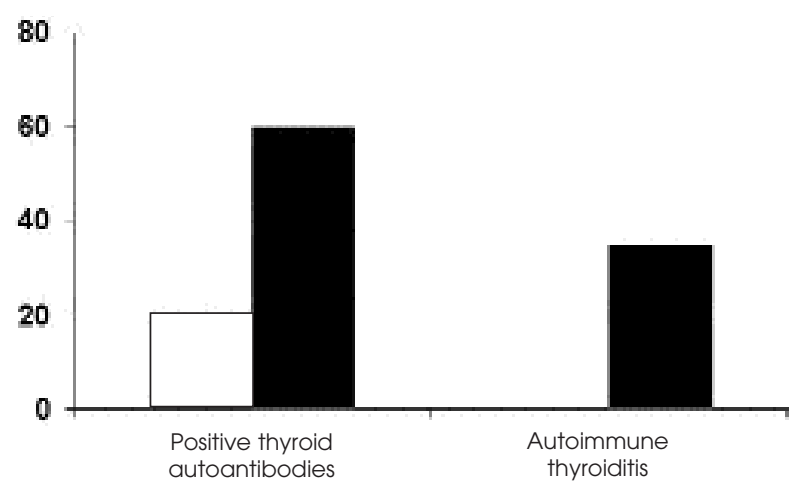

Figure 5. Prevalence of the thyroid autoimmune diseases in patients with active disease (white bars) and one year after disease remission (black bars). 
rebound in immune activity after its prolonged suppression by glucocorticoid excess during the active phase of the disease, suggesting that immune function needs to be accurately monitored in patients with CS after disease remission.

\section{Endocrine diseases}

A secondary hypothyroidism and hypogonadism is commonly found in patients with CS, due to the functional suppression of thyrotropin and gonadotrophin secretion by glucocorticoid excess (1-4). Theoretically, the normalization of cortisol secretion is concomitant to a complete recovery of these endocrine abnormalities, unless a structural damage of the residual pituitary gland occurs after surgical removal of the pituitary tumor, and induces hormone deficiencies in patients with CD (28). The usual recovery of a normal menstrual cycle in women and normal sexual activity in men testifies the reinstatement of normal gonadotropin secretion, suggesting that the rare persistence of these pituitary hormone deficiencies is a direct complication of pituitary surgery, as also supported by the evidence that it occurs almost exclusively in patients with CD. It is important to outline that hypopituitarism occurs in a variable percentage of patients with $C D$ after surgery, in dependence on type of intervention (adenomectomy, hemihypophysectomy or total hypophysectomy) and the amount of removed pituitary gland, being thyrotropin and gonadotropin deficiencies the most common pituitary insufficiencies, requiring replacement treatment (28). It is noteworthy that a certain number of patients with CD display hypocortisolism after treatment, requiring life-long replacement treatment with exogenous glucocorticoids. Finally, $\mathrm{GH}$ deficiency, post-operatively evaluated by dynamic stimulation tests, has been demonstrated to be the most frequent pituitary hormone deficiency, occurring in around $60 \%$ of patients with CD after successful surgical treatment (81-83). This seems to be due to either the long period of time necessary for the restoration of physiological GH secretion after normalization of cortisol secretion and the high prevalence of GH deficiency after pituitary surgery. No systematic study has evaluated the evolution of primitive thyroid and gonadal diseases associated with CS.

\section{Quality of life}

The great number of clinical complications persisting or developing in patients with CS after successful treatment and consequent normalization of cor- tisol secretion are responsible for the relevant impairment on the quality of life documented in patients cured from CS, mainly those who are in remission from $\operatorname{CD}(6,25,84,85)$. In particular, these patients experience considerable physical and psychosocial impairments, especially in the presence of post-operative hypopituitarism, and despite the replacement treatment of the different pituitary deficiencies. The impairment on the quality of life after long-term remission of CD may be explained not only by persisting physical impairments but also by irreversible glucocorticoid-induced changes in the central nervous system or psychological distress of living with a previous disease and treatment. Finally, it cannot be ruled out that long-term endocrine withdrawal effects may have led to irreversible alterations in perceived quality of life.

\section{CONCLUSIONS}

CS is a severe systemic disease associated to multiple clinical complications, which severely impair the quality of life and increased the morbidity and mortality for cardiovascular diseases. The most common form of $\mathrm{CS}$ is $\mathrm{CD}$, due to a corticotroph pituitary tumor, which is associated to several difficulties in the diagnostic and therapeutic procedures and, therefore, to a prolonged exposure to glucocorticoid excess, which makes the pituitary-dependent CS more prone to chronic and permanent complications. The remission of CS is followed by a significant but partial improvement on the clinical syndrome and associated systemic clinical complications, which often persists for a long period of time after disease remission. Moreover, the rapid normalization of cortisol secretion after treatment is frequently followed by the exacerbation or development of novel diseases in predisposed subjects, participating in maintaining the increased morbidity and impaired quality of life of patients cured from CS. These findings suggest the existence of a new syndrome, which can be called "Cushing's cure syndrome", which is partially similar but displays some different characteristics compared to Cushing's syndrome. Figure 6 shows a scheme of the clinical characteristics of this syndrome. Finally, the evidence of this syndrome definitely suggests that patients cured form CS need to be accurately monitored for a long period of time despite normalization of cortisol secretion after successful treatment, probably for the entire life. 


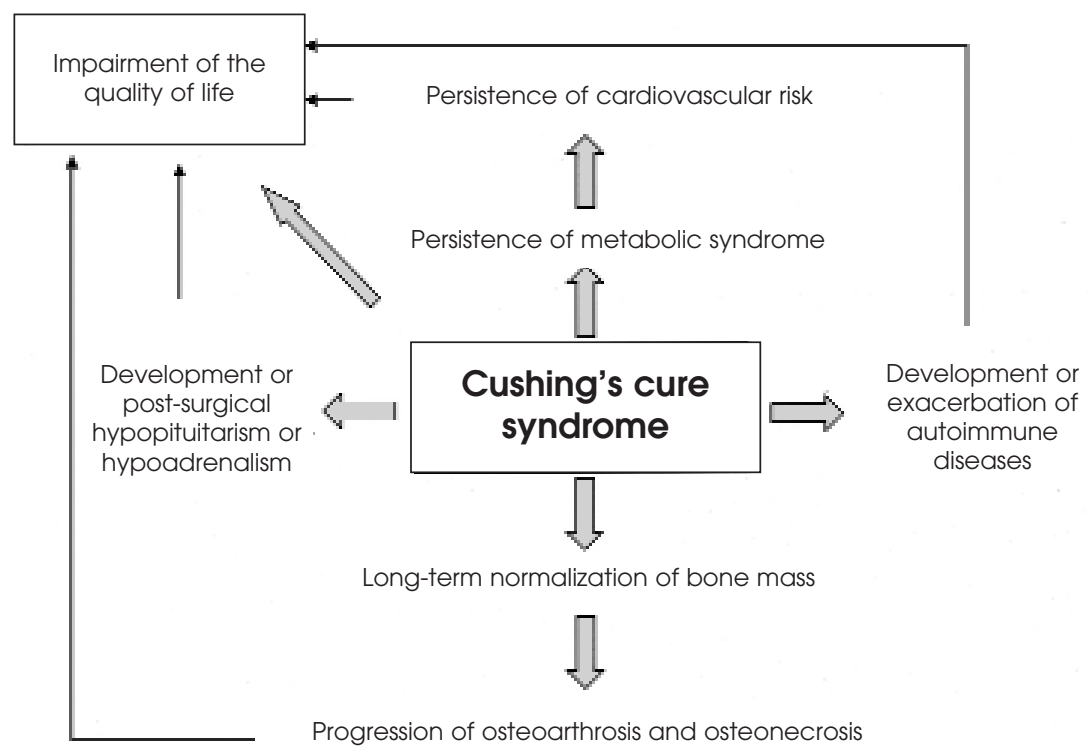

Figure 6. Exemplary scheme of clinical manifestations of the "Cushing's cure syndrome".

\section{REFERENCES}

1. Pivonello R, De Martino MC, De Leo M, Lombardi G, Colao A. Cushing's syndrome. Endocrinol Metab Clin North Am 2007; [in press].

2. Orth DN. Cushing's syndrome. N Engl J Med 1995;332:791803.

3. Arnaldi $G$, Angeli $A$, Atkinson AB, Bertagna $F$, Cavagnini $F$, Chrousos GP, et al. Diagnosis and complications of Cushing's syndrome: A consensus statement. J Clin Endocrinol Metab 2003;88:5593-602.

4. Newell-Price J, Bertagna X, Grossman AB, Nieman LK. Cushing's syndrome. Lancet 2006;367:1605-17.

5. Etxabe J, Vazquez JA. Morbidity and mortality in Cushing's disease: an epidemiological approach. Clin Endocrinol (Oxf) 1994;40:479-84.

6. Pikkarainen L, Sane T, Reunanen A. The survival and wellbeing of patients treated for Cushing's syndrome. J Intern Med 1999;245:463-8.

7. Lindholm J, Juul S, Jørgensen JO, Astrup J, Bjerre P, FeldtRasmussen $\mathrm{U}$, et al. Incidence and late prognosis of Cushing's syndrome: a population-based study. J Clin Endocrinol Metab 2001;86:117-23.

8. Pivonello R, Faggiano A, Lombardi G, Colao A. The metabolic syndrome and cardiovascular risk in Cushing's syndrome. Endocrinol Metab Clin North Am 2005;34;327-9.

9. Faggiano A, Pivonello R, Spiezia S, De Martino MC, Filippella $\mathrm{M}$, Di Somma C, et al. Cardiovascular risk factors and common carotid artery caliber and stiffness in patients with Cushing's disease during active disease and 1 year after disease remission. J Clin Endocrinol Metab 2003; 88:2527-33.

10. Faggiano $A$, Melis $D$, Alfieri $R$, De Martino MC, Filippella $M$, Milone $F$, et al. Sulfur amino acids in Cushing's disease: insight in homocysteine and taurine levels in patients with active and cured disease. J Clin Endocrinol Metab 2005;90:6616-22.

11. Di Somma C, Pivonello R, Loche S, Faggiano A, Marzullo P, Di Sarno $A$, et al. Severe impairment of bone mass and turnover in Cushing's disease: comparison between childhood-onset and adulthood-onset disease. Clin Endocrinol (Oxf) 2002;56:153-8.

12. Tauchmanovà L, Pivonello R, Di Somma C, Rossi R, De Martino MC, Camera $L$, et al. Bone demineralization and vertebral fractures in endogenous cortisol excess: role of disease etiology and gonadal status. J Clin Endocrinol Metab 2006;91:1779-84.
13. Faggiano A, Pivonello R, Filippella M, Di Somma C, Orio F Jr, Lombard G, et al. Spine abnormalities and damage in patients cured from Cushing's disease. Pituitary 2001;4: 15361.

14. Phillips KA, Nance EP Jr, Rodriguez RM, Kaye JJ. Avascular necrosis of bone: a manifestation of Cushing's disease. South Med J 1986;79:825-9.

15. Faggiano A, Pivonello R, Melis D, Filippella M, Di Somma C, Peretta M, et al. Nephrolithiasis in Cushing's disease: prevalence, etiopathogenesis, and modification after disease cure. J Clin Endocrinol Metab 2003;88:2076-80.

16. Faggiano A, Pivonello R, Melis D, Alfieri R, Filippella M, Spagnuolo $G$, et al. Evaluation of circulating levels and renal clearance of natural amino acids in patients with Cushing's disease. J Endocrinol Invest 2002;25:142-51.

17. Sonino N, Fava GA. Psychiatric disorders associated with Cushing's syndrome. Epidemiology, pathophysiology and treatment. CNS Drugs 2001;15:361-73.

18. Bourdeau I, Bard C, Forget $H$, Boulanger $Y$, Cohen $H$, Lacroix A. Cognitive function and cerebral assessment in patients who have Cushing's syndrome. Endocrinol Metab Clin North Am 2005;34:357-69.

19. Mauri M, Sinforiani E, Bono G, Vignati F, Berselli ME, Attanasio R, et al. Memory impairment in Cushing's disease. Acta Neurol Scand 1993;87:52-5.

20. Bourdeau I, Bard C, Noël B, Leclerc I, Cordeau MP, Bélair M, et al. Loss of brain volume in endogenous Cushing's syndrome and its reversibility after correction of hypercortisolism. J Clin Endocrinol Metab 2002;87:1949-54.

21. Niepomniszcze H, Pitoia F, Katz SB, Chervin R, Bruno OD. Primary thyroid disorders in endogenous Cushing's syndrome. Eur J Endocrinol 2002;147:305-11.

22. Lado-Abeal J, Rodriguez-Arnao J, Newell-Price JD, Perry LA, Grossman AB, Besser GM, et al. Menstrual abnormalities in women with Cushing's disease are correlated with hypercortisolemia rather than raised circulating androgen levels. J Clin Endocrinol Metab 1998;83:3083-8.

23. Kaltsas GA, Korbonits M, Isidori AM, Webb JA, Trainer PJ, Monson JP, et al. How common are polycystic ovaries and the polycystic ovarian syndrome in women with Cushing's syndrome? Clin Endocrinol (Oxf) 2000;53:493-500.

24. Giustina A, Wehrenberg WB. The role of glucocorticoids in the regulation of growth hormone secretion. Trends Endocrinol Metab 1992;3:306-11. 
25. Lindsay JR, Nansel T, Baid S, Gumowski J, Nieman LK. Longterm impaired quality of life in Cushing's syndrome despite initial improvement after surgical remission. J Clin Endocrinol Metab 2006;91:447-53.

26. Atkinson AB, Kennedy A, Wiggam MI, McCance DR, Sheridan B. Long-term remission rates after pituitary surgery for Cushing's disease: the need for long-term surveillance. Clin Endocrinol (Oxf) 2005;63:549-59.

27. Newell-Price J. Transsphenoidal surgery for Cushing's disease: defining cure and following outcome. Clin Endocrinol (Oxf) 2002;56:19-21.

28. McCance DR, Besser M, Atkinson AB. Assessment of cure after transsphenoidal surgery for Cushing's disease. Clin Endocrinol (Oxf) 1996;44:1-6.

29. Jeffcoate WJ, Dauncey S, Selby C. Restoration of dexamethasone suppression by incomplete adenomectomy in Cushing's disease. Clin Endocrinol (Oxf) 1985;23:193-9.

30. Estrada J, García-Uría J, Lamas C, Alfaro J, Lucas T, Diez S, et al. The complete normalization of the adrenocortical function as the criterion of cure after transsphenoidal surgery for Cushing's disease. J Clin Endocrinol Metab 2001;86:5695-9.

31. Trainer PJ, Lawrie HS, Verhelst J, Howlett TA, Lowe DG, Grossman AB, et al. Transsphenoidal resection in Cushing's disease: undetectable serum cortisol as the definition of successful treatment. Clin Endocrinol 1993:38:73-8.

32. Yap LB, Turner HE, Adams CB, Wass JA. Undetectable postoperative cortisol does not always predict long-term remission in Cushing's disease: a single centre audit. Clin Endocrinol (Oxf) 2002;56:25-31.

33. Pereira AM, van Aken MO, van Dulken H, Schutte PJ, Biermasz NR, Smit JW, et al. Long-term predictive value of postsurgical cortisol concentrations for cure and risk of recurrence in Cushing's disease. J Clin Endocrinol Metab 2003;88:5858-64.

34. Avgerinos PC, Chrousos GP, Nieman LK, Oldfield EH, Loriaux $\mathrm{DL}$, Cutler GB. The corticotropin releasing hormone test in the postoperative evaluation of patients with Cushing's syndrome. J Clin Endocrinol Metab 1987;65:906-13.

35. Valéro $R$, Vallette-Kasic $S$, Conte-Devolx B, Jaquet $P$, Brue $T$. The desmopressin test as a predictive factor of outcome after pituitary surgery for Cushing's disease. Eur J Endocrinol 2004; 151:727-33.

36. Sacerdote A, Weiss K, Tran T, Rokeya Noor B, McFarlane SI. Hypertension in patients with Cushing's disease: pathophysiology, diagnosis, and management. Curr Hypertens Rep 2005;7:212-8.

37. Fallo F, Sonino N, Barzon L, Pistorello M, Pagotto U, Paoletta $A$, et al. Effect of surgical treatment on hypertension in Cushing's syndrome. Am J Hypertens 1996;9:77-80.

38. Magiakou MA, Mastorakos G, Zachman K, Chrousos GP. Blood pressure in children and adolescents with Cushing's syndrome before and after surgical care. J Clin Endocrinol Metab 1997;82:1734-8.

39. Suzuki T, Shibata H, Ando T, Kurihara I, Kobayashi S, Hayashi $\mathrm{K}$, et al. Risk factors associated with persistent postoperative hypertension in Cushing's syndrome. Endocr Res 2000;26:791-5.

40. Colao A, Pivonello R, Spiezia S, Faggiano A, Ferone D, Filippella $M$, et al. Persistence of increased cardiovascular risk in patients with Cushing's disease after five years of successful cure. J Clin Endocrinol Metab 1999;84:2664-72.

41. Wake DJ, Walker BR. 11 beta-hydroxysteroid dehydrogenase type 1 in obesity and the metabolic syndrome. Mol Cell Endocrinol 2004;215:45-54.

42. Walker BR. Cortisol - cause and cure for metabolic syndrome? Diabet Med 2006;23:1281-8.

43. Mancini T, Kola B, Mantero F, Boscaro M, Arnaldi G. High cardiovascular risk in patients with Cushing's syndrome according to $1999 \mathrm{WHO} / \mathrm{ISH}$ guidelines. Clin Endocrinol (Oxf) 2004;61:768-77.

44. Dal Bo Zanon R, Fornasiero L, Boscaro M, Cappellato G, Fabris F, Girolami A. Increased factor VIII associated activities in Cushing's syndrome: a probable hypercoagulable state. Thromb Haemost 1982;47:116-7.
45. Patrassi GM, Sartori MT, Viero ML, Scarano L, Boscaro M, Girolami A. The fibrinolytic potential in patients with Cushing's disease: a clue to their hypercoagulable state. Blood Coagul Fibrinolysis 1992;3:789-93.

46. Boscaro M, Sonino N, Scarda A, Barzon L, Fallo F, Sartori MT, et al. Anticoagulant prophylaxis markedly reduces thromboembolic complications in Cushing's syndrome. J Clin Endocrinol Metab 2002;87:3662-6.

47. Ohmori N, Nomura K, Ohmori K, Kato Y, Itoh T, Takano K. Osteoporosis is more prevalent in adrenal than in pituitary Cushing's syndrome. Endocr J 2003;50:1-7.

48. Minetto M, Reimondo G, Osella G, Ventura M, Angeli A, Terzolo $\mathrm{M}$. Bone loss is more severe in primary adrenal than in pituitary-dependent Cushing's syndrome. Osteoporos Int 2004; 11:855-61.

49. Mazziotti G, Angeli A, Bilezikian JP, Canalis E, Giustina A. Glucocorticoid-induced osteoporosis: an update. Trends Endocrinol Metab 2006;17:144-9.

50. Manning PJ, Evans MC, Reid IR. Normal bone mineral density following cure of Cushing's syndrome. Clin Endocrinol (Oxf) 1992;36:229-34.

51. Hermus AR, Smals AG, Swinkels LM, Huysmans DA, Pieters GF, Sweep CF, et al. Bone mineral density and bone turnover before and after surgical cure of Cushing's syndrome. J Clin Endocrinol Metab 1995;80:2859-65.

52. Di Somma C, Pivonello R, Loche S, Faggiano A, Klain M, Salvatore $M$, et al. Effect of 2 years of cortisol normalization on the impaired bone mass and turnover in adolescent and adult patients with Cushing's disease: a prospective study. Clin Endocrinol (Oxf) 2003;58:302-8.

53. Kristo $C$, Jemtland $R$, Ueland $T$, Godang $K$, Bollerslev J. Restoration of the coupling process and normalization of bone mass following successful treatment of endogenous Cushing's syndrome: a prospective, long-term study. Eur J Endocrinol 2006; $154: 109-18$.

54. Gozzi TG, Simm PJ, Cameron FJ. Spontaneous recovery of steroid-induced osteopenia. J Paediatr Child Health 2006; $42: 68-9$.

55. Di Somma C, Colao A, Pivonello R, Klain M, Faggiano A, Tripodi FS, et al. Effectiveness of chronic treatment with alendronate in the osteoporosis of Cushing's disease. Clin Endocrinol (Oxf) 1998;48:655-62.

56. Takada J, Nagoya S, Kuwabara H, Kaya M, Yamashita T. Rapidly destructive coxarthropathy with osteonecrosis and osteoporosis caused by Cushing's syndrome. Orthopedics 2004; $27: 1111-3$

57. Kingsley GH, Hickling P. Polyarthropathy associated with Cushing's disease. Br Med J 1986;292:1363.

58. Sharon P, Kaplinsky N, Leiba S, Frankl O. Aseptic necrosis of head of femur: presenting manifestation in Cushing's disease. J Rheumatol 1977;4:73-5.

59. Koch CA, Tsigos C, Patronas NJ, Papanicolaou DA. Cushing's disease presenting with avascular necrosis of the hip: an orthopedic emergency. J Clin Endocrinol Metab 1999;84:3010-2.

60. Momose KJ, Kjellberg RN, Kliman B. High incidence of cortical atrophy of the cerebral and cerebellar hemispheres in Cushing's disease. Radiology 1971;99:341-8.

61. Starkman MN, Gebarski SS, Berent S, Schteingart DE. Hippocampal formation volume, memory dysfunction, and cortisol levels in patients with Cushing's syndrome. Biol Psychiatry 1992;32:756-65.

62. Simmons NE, Do HM, Lipper MH, Laws Jr ER. Cerebral atrophy in Cushing's disease. Surg Neurol 2000;53:72-6.

63. Heinz ER, Martinez J, Haenggeli A. Reversibility of cerebral atrophy in anorexia nervosa and Cushing's syndrome. J Comput Assist Tomogr 1977;1:415-8.

64. Starkman MN, Giordani B, Gebarski SS, Berent S, Schork MA, Schteingart DE. Decrease in cortisol reverses human hippocampal atrophy following treatment of Cushing's disease. Biol Psychiatry 1999;46:1595-602.

65. Starkman MN, Schteingart DE, Schork MA. Cushing's syndrome after treatment: changes in cortisol and ACTH levels, and amelioration of the depressive syndrome. Psychiatry Res 1986;19:177-88. 
66. Kelly WF, Kelly MJ, Faragher B. A prospective study of psychiatric and psychological aspects of Cushing's syndrome. Clin Endocrinol 1996;45:715-20.

67. Dorn LD, Burgess ES, Friedman TC, Dubbert B, Gold PW, Chrousos GP. The longitudinal course of psychopathology in Cushing's syndrome after correction of hypercortisolism. J Clin Endocrinol Metab 1997;82:912-9.

68. Wolkowitz OM, Reus VI. Treatment of depression with antiglucocorticoid drugs. Psychosom Med 1999;61:698711.

69. Forget $H$, Lacroix $A$, Cohen $H$. Persistent cognitive impairment following surgical treatment of Cushing's syndrome. Psychoneuroendocrinology 2002;27:367-83.

70. Merke DP, Giedd JN, Keil MF, Mehlinger SL, Wiggs EA, Holzer $\mathrm{S}$, et al. Children experience cognitive decline despite reversal of brain atrophy one year after resolution of Cushing's syndrome. J Clin Endocrinol Metab 2005;90:2531-6.

71. Dougherty TF. Effect of hormones on lymphatic tissue. Physiol Rev 1995;232:379-401.

72. Bateman A, Singh A, Kral T, Solomon S. The immune hypothalamic-pituitary-adrenal axis. Endocr Rev 1989;10:92-112.

73. Candrina R, Di Stefano O. Exacerbation of celiac disease after cure of Cushing's disease. Am J Med 1993;95:341.

74. Steuer A, Cavan DA, Lowy C. Sarcoidosis presenting after resection of an adrenocortical adenoma. Br Med J 1995;310:567-8.

75. Yakushiji F, Kita M, Hiroi N, Ueshiba H, Monma I, Miyachi Y. Exacerbation of rheumatoid arthritis after removal of adrenal adenoma in Cushing's syndrome. Endocr J 1995;42:219-23.

76. Naguchi Y, Tamai H, Fujishawa K, Nagawo J, Mukuta T, Komaki G, et al. Systematic lupus erythmatosus after pituitary adenomectomy in a patient with Cushing's disease. Clin Endocrinol (Oxf) 1998;48:670-2.

77. Takasu N, Komiya I, Nagasawa Y, Asawa T, Yamada T. Exacerbation of autoimmune thyroid dysfunction after unilateral adrenalectomy in patients with Cushing's syndrome due to an adrenocortical adenoma. N Engl J Med 1990; 322:1708-12.

78. Takasu N, Ohara N, Yamada T, Komiya I. Development of autoimmune thyroid dysfunction after bilateral adrenalectomy in a patient with Carney's complex and after removal of ACTH-producing pituitary adenoma in a patient with Cushing's disease. J Endocrinol Invest 1993;16:691-702.
79. Morita H, Isaji M, Mune T, Daido H, Isomura $Y$, Sarui H, et al. Transient Graves disease developing after surgery for Cushing disease. Am J Med Sci 2002;323:162-5.

80. Colao A, Pivonello R, Faggiano A, Filippella M, Ferone D, Di Somma C, et al. Increased prevalence of thyroid autoimmunity in patients successfully treated for Cushing's disease. Clin Endocrinol (Oxf) 2000;53:13-9.

81. Hughes NR, Lissett CA, Shalet SM. Growth hormone status following treatment for Cushing's syndrome. Clin Endocrinol (Oxf) 1999;51:61-6.

82. Tzanela M, Karavitaki N, Stylianidou C, Tsagarakis S, Thalassinos NC. Assessment of GH reserve before and after successful treatment of adult patients with Cushing's syndrome. Clin Endocrinol (Oxf) 2004;60:309-14.

83. Pecori Giraldi F, Andrioli M, De Marinis L, Bianchi A, Giampietro $A$, De Martin M, et al. Significant GH deficiency after long-term cure by surgery in adult patients with Cushing's disease. Eur J Endocrinol 2007;156:233-9.

84. Heald AH, Ghosh S, Bray S, Gibson C, Anderson SG, Buckler $H$, et al. Long-term negative impact on quality of life in patients with successfully treated Cushing's disease. Clin Endocrinol (Oxf) 2004;61:458-65.

85. van Aken MO, Pereira AM, Biermasz NR, van Thiel SW, Hoftijzer HC, Smit JWA, et al. Quality of life in patients after longterm biochemical cure of Cushing's disease. J Clin Endocrinol Metab 2005;90:3279-86.

Address for correspondence:

Rosario Pivonello

Department of Molecular and Clinical Endocrinology and

Oncology

Federico II University

Via Sergio Pansini, 5

80131 Naples, Italy

Fax: (+39) 0815465443

E-mail: rpivone@tin.it 